\title{
CuI Film Produced by Chemical Extraction Method in Different Media
}

\author{
Ishak Afşin Kariper * \\ ${ }^{a}$ Education Faculty, Erciyes University, 38039, Kayseri, Turkey
}

Received: January 26, 2016; Revised: May 12, 2016; Accepted: June 25, 2016

\begin{abstract}
CuI crystalline thin films were produced on substrates (commercial glass) using chemical extraction method in different chemical bath media. In this study, their structural, optical and electrical properties were analyzed. Transmittance, absorption, optical band gap and refractive index of the films were examined by UV/VIS spectrum. XRD data showed that the film has a hexagonal structure for CuI. Surface and elemental (in terms of ratio) analysis of the films were performed via SEM and EDX analysis. The highest average grain size of $\mathrm{CuI}$ was observed for the film produced in aqueous media whereas the lowest average grain size was seen in chloroform bath. The curve formed by the number of crystallites per unit area $(\mathrm{N})$ is different than the curves of dislocation density and average grain size. Number of crystallites per unit area has reached its maximum value in $\mathrm{CCl} 4$ bath, but it has been decreased in chloroform bath. In addition, film thickness has varied between $1232 \mathrm{~nm}$ and $3624 \mathrm{~nm}$ according to the solvent of bath.
\end{abstract}

Keywords: CuI films, Chrystal growth, Thin film, Optical properties

\section{Introduction}

Copper iodine is a metal halide such as $\mathrm{AgI}, \mathrm{PbI}_{2}$, etc... Similar to AgI, Copper iodine has three crystalline phases $\alpha, \beta, \gamma^{1-4}$. In $\alpha$-phase, $\mathrm{CuI}$ has a cubic structure and it is conductive because of copper ions ${ }^{1}$. In $\beta$-phase, it has a hexagonal structure and ionic conductivity is observed, whereas in $\gamma$-phase, cubic structure with $p$-type semiconducting has been observed. These phases change with temperature; in the literature it has been stated that $\mathrm{CuI}$ is at $\alpha$-phase up to $392^{\circ} \mathrm{C}$, whereas it switches to the $\gamma$-phase at below $350^{\circ} \mathrm{C}$. CuI shows P-type semi conductivity depending on the excess iodine in its structure and the band gap was determined as $3.1 \mathrm{eV}^{2-4}$.

Copper iodine thin films are used in photovoltaic cells, cathodic dye-sensitization and electrolytic methods ${ }^{5-7}$. Researchers have worked on copper iodine by using different methods, both chemical (in water and ethanol) and physical ${ }^{8-10}$. But nobody has investigated $\mathrm{CuI}$ thin films produced via chemical extraction method up to now, so we are unaware of how the bath conditions will impact CuI film structure, as well as its optical and electrical properties. Producing CuI thin film via chemical bath deposition is quite difficult, because copper ions are reduced by iodine, consequently contamination of iodine decreases with the formation of copper iodine.

* e-mail: akariper@gmail.com
The aim of this paper is to produce $\mathrm{CuI}$ thin film via chemical extraction method and examine its structural and optical properties. In this study, we attempted to show that optical and structural properties of CuI could be controlled by changing the media in which $\mathrm{CuI}$ films are produced. Since no one has worked on CuI thin film produced via chemical extraction method, we were unaware of how different bath environment might affect $\mathrm{CuI}$ film structure and its optical properties.

\section{Experimental}

The components of bath were $1 \%(\mathrm{w} / \mathrm{v})$ nitric acid, $0.005 \mathrm{M}$ copper nitrate hemi hydrate and $0.015 \mathrm{M}$ potassium iodide. First, $100 \mathrm{~mL} 0.015 \mathrm{M}$ potassium iodide was prepared as a stock solution using different solvents, namely water, ethanol, $\mathrm{CCl}_{4}$ and chloroform; then $0.005 \mathrm{M}$ copper ion stock solution was prepared. $10 \mathrm{ml} 0.005 \mathrm{M}$ copper nitrate hemi hydrate and $10 \mathrm{ml} 0.015 \mathrm{M}$ potassium iodide (each time prepared with different solvents) were put in the beakers. Iodide solutions used in chemical baths were prepared with different solvents. The deposition temperature of chemical baths was $50^{\circ} \mathrm{C}$ and the deposition time was 4 hours. After taking the films out of the bath, each of them was washed with the solvent forming the base of the iodine solution, in order to get rid of iodine ions that might have been adhered to the surface. Figure 1a shows the production of the films 


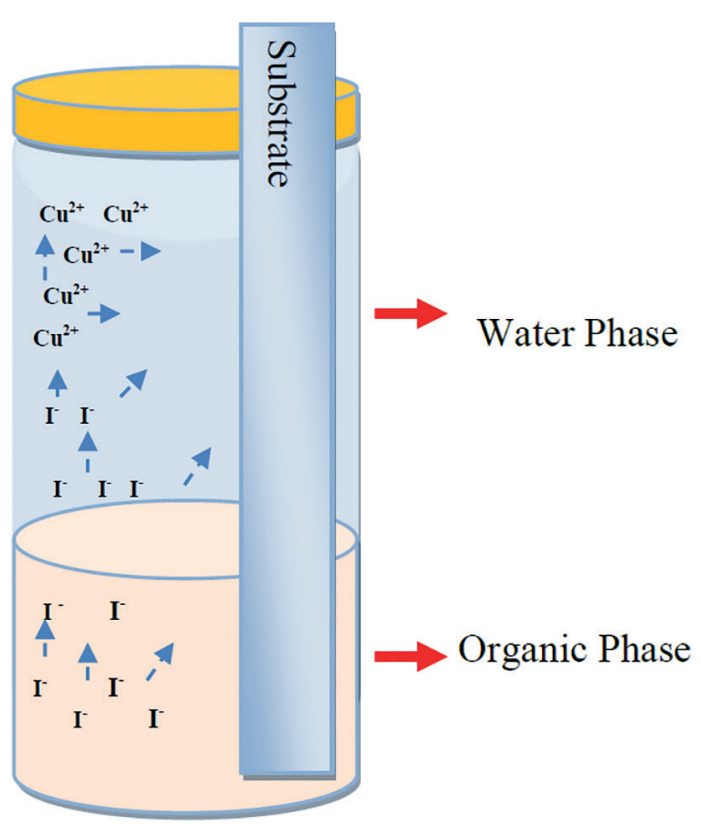

Fig 1. a.

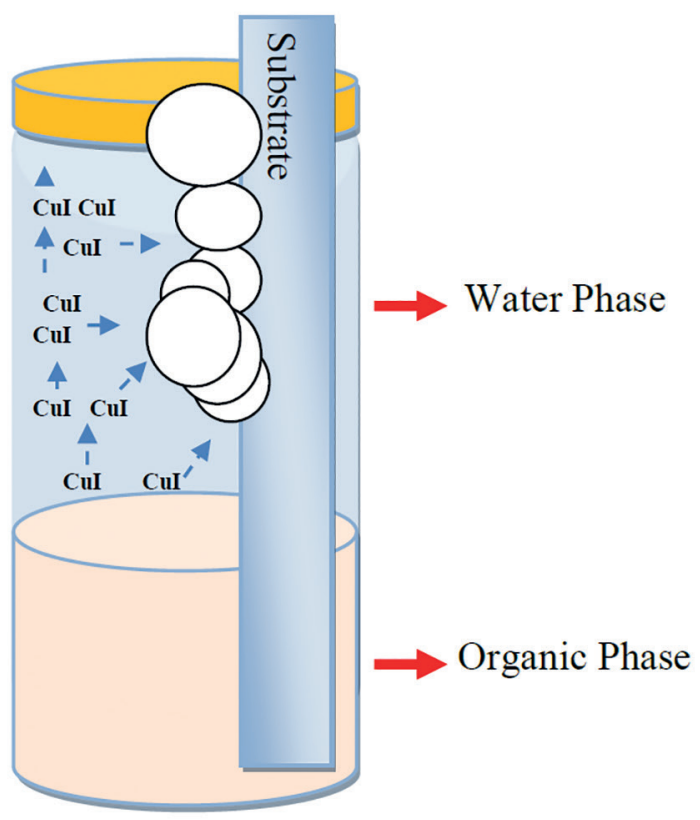

Fig 1. b.

Figure 1: Chemical Extraction Method and Chemical Bath Deposition

via Chemical Extraction Method with organic solvents whereas Figure 1b shows chemical extraction deposition resulted after this process.

The crystalline structure of $\mathrm{CuI}$ was confirmed by $\mathrm{X}$-ray diffraction $(\mathrm{XRD})$ with a $\mathrm{CuK} \alpha_{1}$ radiation source (Rikagu RadB model, $\lambda=1.5406 \AA$ ) over the range $10^{\circ}$ $<2 \theta<90^{\circ}$ at a speed of $3^{\circ} \mathrm{min}^{-1}$ with a step size of $0.02^{\circ}$. The surface properties of the films were examined by using an EVO40-LEO computer controlled digital scanning electron microscope (SEM). Film thicknesses were measured with a Veeco Multi Mode AFM (Controller=NanoScope 3D). Thicknesses were measured in a $10 \times 10 \mu \mathrm{m}$ area with tapping mode. The optical measurements were performed by Hach Lange DR 5000 Spectrophotometer at room temperature by placing an uncoated identical commercial glass substrate to the reference beam. The optical spectrum of thin films was recorded at the range of 300-1100 nm wavelength.

\section{Results and Discussion}

The chemical reactions regarding the deposition of copper iodine films, which occurred in the bath, are shown below. Copper ions $\left(\mathrm{Cu}^{+2}\right)$ are combined with iodine $(\mathrm{I})$ in order to form the insoluble $\mathrm{CuI}$ in the bath.

$$
\begin{array}{r}
\mathrm{H}_{3} \mathrm{O}^{+}+\mathrm{I}^{-}-\mathrm{H}_{2} \mathrm{O}+\mathrm{HI} \quad \text { (in water) } \\
\mathrm{Cu}^{+2}+3 \mathrm{I}^{-} \rightarrow \mathrm{CuI}_{(\mathrm{k})}+\mathrm{I}_{2(s)}
\end{array}
$$

The production of copper iodine was not similar to producing other metal halides, because, the solid iodide formed in the bath was giving a dark red color to the solution. Then, iodide should be separated from copper iodine thin film and should be purified. Accordingly, Iodine ions adhered to the surface of $\mathrm{CuI}$ has been removed and the amount of iodine ions was reduced. Thus, performing the production in aqueous media may not always be the right way for thin films where a very good purification is required, of course without damaging the film. We didn't even need to do it because excess iodine was not seen much in chloroform, carbon tetra chloride, and ethanol media. Iodine passes to aqueous media before the equilibrium is established. The main problem was that these solvents might also remove copper iodine thin film from the substrate. Thus, we should decide about which solvent is correct. In other words, the quality of CuI films depends on the media of chemical bath.

XRD patterns of CuI films deposited via CBD in different bath media are presented in Figure 2 and hkl values are presented in Table 1. Structural properties were calculated by Scherrer formula with the following variables; grain size (D), dislocation density $(\delta)$, and number of crystallites per unit area $(\mathrm{N})$. Lattice parameters along (220), (102), (200), (103) plane were calculated by using the formulas given below ${ }^{11-15}$ :

$$
\begin{gathered}
D=\frac{0.9 \lambda}{B \cos \theta} \\
\delta=\frac{1}{D^{2}}
\end{gathered}
$$




$$
\begin{gathered}
\mathrm{d}^{2}=\frac{1}{\frac{4\left(\mathrm{~h}^{2}+\mathrm{hk}+\mathrm{l}^{2}\right)}{3 \mathrm{a}^{2}}+\frac{\mathrm{l}^{2}}{\mathrm{c}^{2}}} \quad \text { (Hexagonal Structure) } \\
N=\frac{t}{D^{3}} \quad(6)
\end{gathered}
$$

Where $\mathrm{t}$ is film thickness, $\lambda$ is wavelength of $\mathrm{X}$-ray used (1.5406 $\AA$ ), $\beta$ is FWHM of the peak, $\theta$ is Bragg angle, $\delta$ is dislocation density which is defined as the length of dislocation lines per unit volume of the crystal, $\mathrm{N}$ is number of crystallites per unit area. Higher $\mathrm{N}$ value indicates an abundance of crystallization. Average grain size of $\mathrm{CuI}$ has varied according to the media of the bath. The change of dislocation density and number of crystallites per unit area for each bath media are displayed in Figure 3.

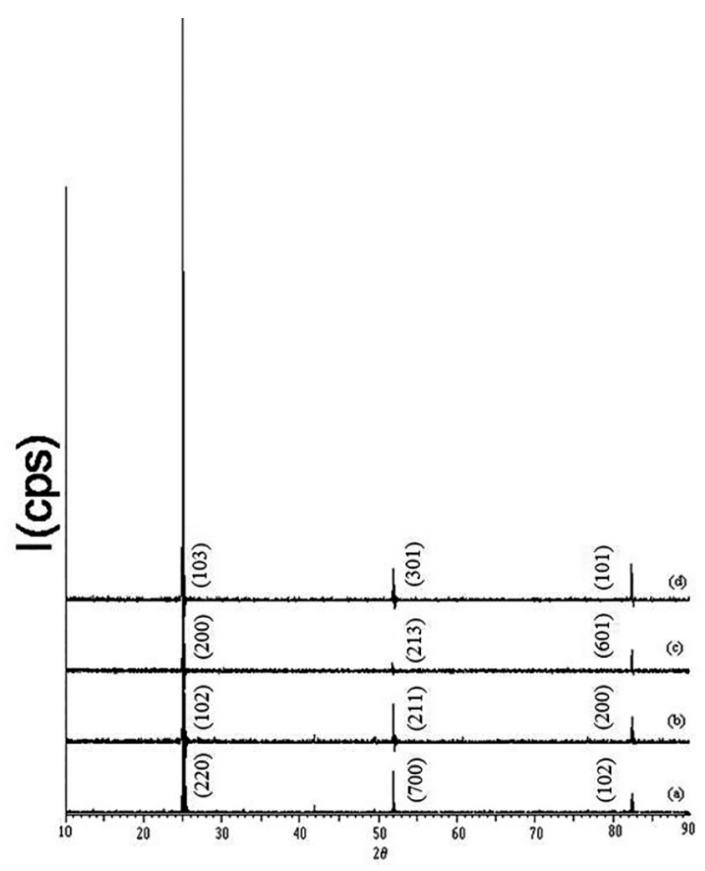

Figure 2: XRD patterns of $\mathrm{CuI}$ thin films formed in different media of chemical bath (a) water, (b) ethanol, (c) chloroform, (d) carbon tetrachloride

Maximum peaks of the films with $\gamma$-CuI structure, were observed at 24-25 $2 \theta$ degree. Z. Zheng et al. produced $\mathrm{CuI}$ thin films via sonochemical method and they observed maximum peaks at 43.12-50.32 $(\theta)$ degree. They also observed peaks at 25.16-42.02 $(\theta)$ degree. K. Tennakone et al. also produced $\mathrm{CuI}$ films in aqueous media, on glass substrates. The film that they have produced had $\gamma$-CuI structure and they identified maximum peaks at $25.563(\theta)$ degrees $^{8}$. In fact, all our peaks are compatible with ASTM data files; their structures could be easily elucidated by indexing via XRD EVA program. Actually, it is not possible to find $\mathrm{CuI}$ films produced via chemical extraction method, on amorphous glasses with so obvious and clearly marked XRD peaks in the literature.
Table 1: XRD patterns of CuI thin films formed in different chemical bath media.

\begin{tabular}{lcccc}
\hline $\begin{array}{l}\text { Preparing } \\
\text { Solutions }\end{array}$ & $(\mathrm{hkl})$ & $\begin{array}{c}2 \theta \\
\text { (Observed })\end{array}$ & $\begin{array}{c}2 \theta \\
\text { (Calculated })\end{array}$ & $\mathrm{I} / \mathrm{I}_{\mathrm{o}}$ \\
\hline \multirow{4}{*}{ Water } & 301 & 24.800 & 24.803 & 17.3 \\
& 220 & 25.060 & 25.021 & 100.0 \\
& 102 & 25.220 & 25.212 & 35.4 \\
& 700 & 51.920 & 51.917 & 12.4 \\
& 102 & 82.497 & 82.500 & 5.8 \\
Ethanol & 003 & 24.781 & 24.790 & 25.8 \\
& 102 & 25.060 & 25.074 & 100.0 \\
& 211 & 51.918 & 51.918 & 15.8 \\
& 200 & 82.440 & 82.439 & 10.5 \\
& 200 & 25.000 & 25.014 & 100.0 \\
& 111 & 25.120 & 25.123 & 13.2 \\
& 213 & 51.860 & 51.860 & 2.8 \\
& 601 & 82.440 & 82.439 & 6.8 \\
& 004 & 24.740 & 24.742 & 8.8 \\
& 103 & 24.980 & 24.980 & 100.0 \\
& 301 & 51.896 & 51.896 & 5.4 \\
& 101 & 82.421 & 82.421 & 5.9 \\
\hline
\end{tabular}

We even didn't need to clean the raw data that we have received from EVA program ${ }^{16}$. Of course, there is a difference between these degrees and the ones in the literature, which occurred because of different crystalline orientations formed due to different production methods. But, these values are not very big; these are the deviations acceptable by the international literature. These results were in agreement with the literature.

The highest and sharpest peaks were observed in water and ethanol, and presented in Figure 1. Hexagonal structure was seen in all $\mathrm{CuI}$ thin films. The biggest average grain size of $\mathrm{CuI}$ was observed in the film formed in the water bath, as $64 \mathrm{~nm}$ while the smallest was observed as $33 \mathrm{~nm}$ in the film from the chloroform bath. This is because the solubility of $\mathrm{Cu}^{2+}$ and $\mathrm{I}^{-}$ions is lower in water and alcohol, compared to chloroform. If CuI, which was formed in these phases, is not dissolved easily in the solvent, it precipitates fast and causes the crystal to overgrowth on the surface of the substrate. The solubility of ionic types and $\mathrm{CuI}$ is a bit higher in chloroform compared to the other phases, which resulted with the formation of smaller crystals. The lowest dislocation density $(\delta)$ of $\mathrm{CuI}$ was calculated for the film prepared in water bath, whereas the highest dislocation density $(\delta)$ was found for the one formed in chloroform bath, as presented in Figure 2. Number of crystallites per unit area (N) of CuI had a different curve than dislocation density and average grain size. Number of crystallites per unit area of $\mathrm{CuI}$ reached its maximum value in the film obtained from the $\mathrm{CCl}_{4}$ bath, but decreased in the one obtained from the chloroform bath. 

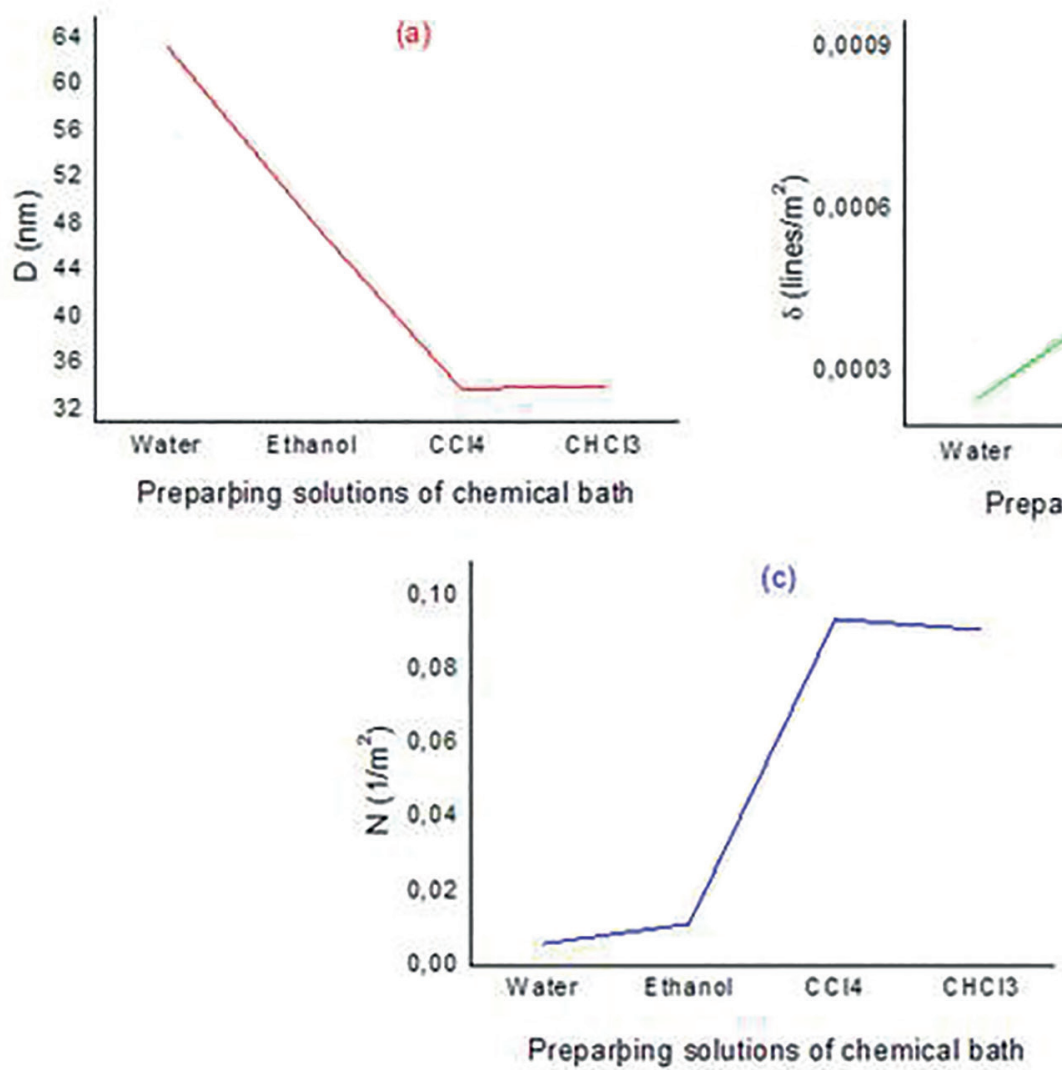

(c)

Figure 3: Average crystallite size (a), dislocation density (b), and number of crystallites per unit area (c) of CuI produced in different chemical bath media.

This result showed that the film thickness has been increased in chloroform bath. Regarding the utilization of carbon tetra chloride and chloroform, since they are immiscible with water, copper ions stayed in the water whereas iodide ions stayed in the solvent. This fact let us reflect if the film can be produced on the surface via the extraction process, a method very well-known by chemists. Although copper ions cannot pass into carbon tetra chloride and chloroform media, the transition of iodine to another media, such as water or ethanol, is possible. So, we took iodine from the other solvents, and we performed a very different extraction process in the aqueous media enriched by $\mathrm{CuI}$. Chloroform has a polar structure, whereas the structure of carbon tetra chloride is apolar. Thus, iodide ions in the chloroform pass to aqueous media better than iodide ions in carbon tetra chloride. Therefore, because of the increased concentration of iodine in the water, $\mathrm{CuI}$ precipitation has been formed. While the film is formed on the substrate's surface, the amount of $\mathrm{CuI}$ in the water decreases and a portion of it formed a precipitate. In this event, the increase of the amount of iodine in the aqueous media will affect the film thickness depending on the extraction process. This effect is shown in Figure 4. However, since the whole substrate would not be
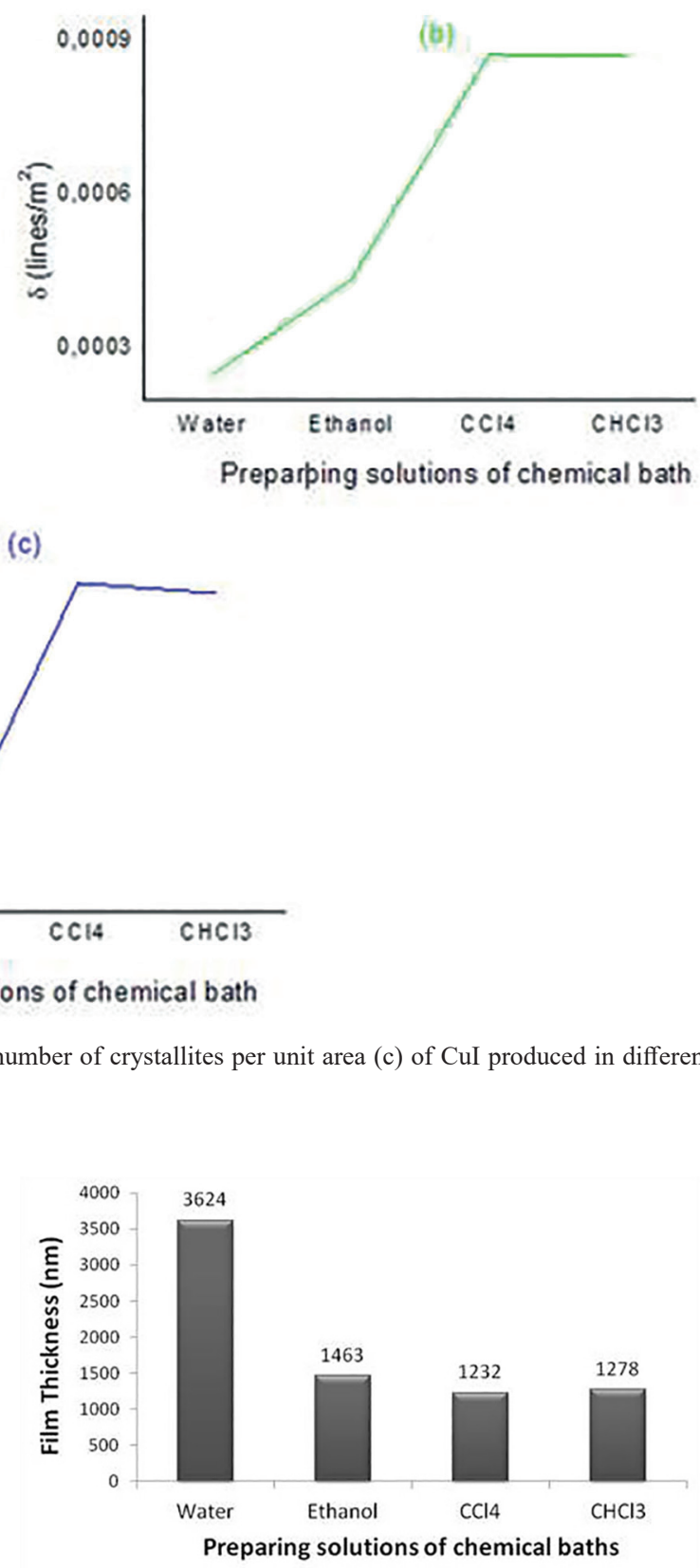

Figure 4: Film thickness of CuI thin films.

covered with the film, we had to cut a part of the substrate (the part stayed in the other solvent). But still, about half of the substrate was covered with the film.

The transmittance $(\mathrm{T})$ for CuI thin film can be calculated by using reflectivity (R) and absorbance (A) spectra from the expression ${ }^{16}$ :

$$
T=(1-R)^{2} e^{-A}
$$

Transmission and absorption were measured at room conditions, by scanning at the range of 300-1100 nm wavelength and the results are shown in Figure 5. Chemical 
baths were prepared with different solvents. Therefore, transmissions of the films produced in different media have varied. Transmission of the film produced in chloroform bath was the highest whereas the one produced in water bath was the lowest. As mentioned above, the formation of smaller particles in chloroform media causes the films produced in this media to absorb the light less. The transmission of the materials, which absorb light less, is lower. As expected, reflectivity curves of $\mathrm{CuI}$ thin films were just opposite of the transmittance curves. Optical transmission of the film produced in water bath was $63 \%$, whereas optical transmission of the film produced in chloroform bath was $79 \%$ (550 nm wavelengths). Reflectivity of the film produced in water bath was $12 \%$, whereas reflectivity of the film produced in chloroform bath was $6 \%$ (550 nm wavelengths). Transmission increased with film thickness whereas reflection decreased with it.

Y. Yan et al. produced CuI via spraying method. They produced $\mathrm{CuI}$ having $35 \mathrm{~nm}$ grain sizes, with 65 $\%$ transmittance ${ }^{17}$. The results of the films obtained from chloroform and carbon tetra chloride baths were in accordance with the literature regarding grain size and transmittance.

Refractive index and extinction coefficient of the films are given by the following formulas ${ }^{16}$ :

$$
\begin{gathered}
n=\frac{(1+R)}{1-R}+\sqrt{\frac{4 R}{(1-R)^{2}}-k^{2}} \\
k=\frac{\alpha \lambda}{4 \pi} \quad(9)
\end{gathered}
$$

Refractive index and extinction coefficient of $\mathrm{CuI}$ thin films are shown in Figure 6. Refractive index were 2.05, 2.02, 1.74 and 1.66 , for the films produced in water, ethanol, carbon tetra chloride and chloroform solutions, and it is displayed in Figure 5 (550 nm wavelength). Similarly, the refractive index of the film produced in the chloroform bath, in which particle size was comparably smaller than the others, is lower. On the other hand, extinction coefficient behaved as refractive index and took values $0.014,0,013,0.008$ and 0.007 , for the films produced in the baths prepared with water, ethanol, carbon tetra chloride and chloroform, respectively (550 nm wavelength). Refractive index and extinction coefficient of $\mathrm{CuI}$ thin films were directly proportional to film thickness.

Scanning electron microscopy (SEM) was used to examine the effect of the bath media on the properties of film surface, as the surface properties directly affected electrical and optical properties of the films. SEM images of $\mathrm{CuI}$ thin films produced in different baths are presented in Figure 7. SEM analysis provided more accurate information about grain structure. As can be seen in Figure $7 \mathrm{a}-\mathrm{d}$, the size of crystallites is smaller for the films produced in chloroform and carbon tetra chloride solutions. The biggest grains were observed for the film produced in water bath. All films had insular structure (island) and had strong adherence to substrates. It can be seen in Figure $7 \mathrm{~b}$ and $7 \mathrm{c}$ that in some areas $\mathrm{CuI}$ nanoparticles were gathered together.

These surface properties have strong effects on the optical properties of the films, such as transmittance, absorbance and reflection. So, it is seen that surface properties of $\mathrm{CuI}$

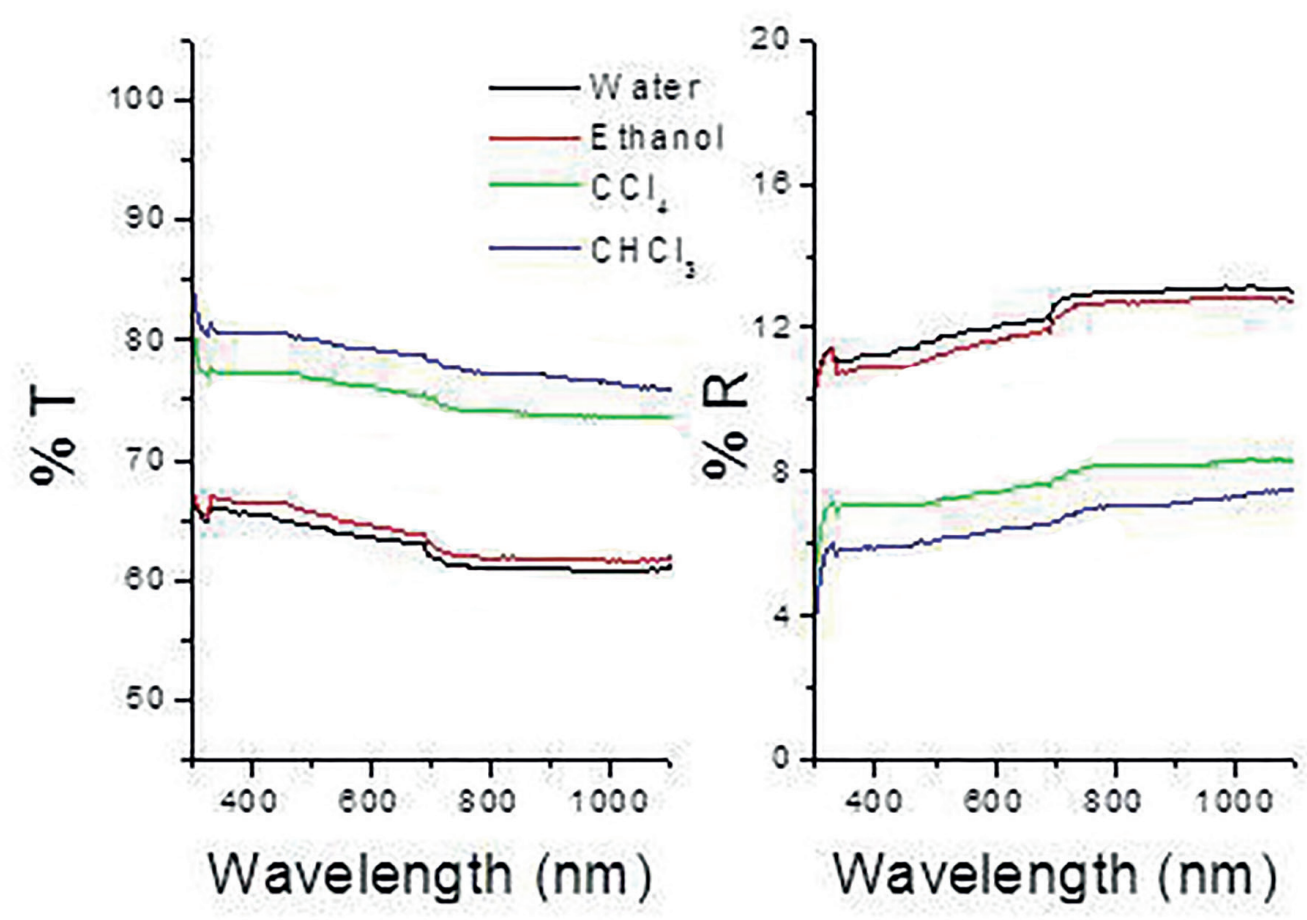

Figure 5: Transmittance (T) and reflectivity (R) of CuI thin films produced in different media. 

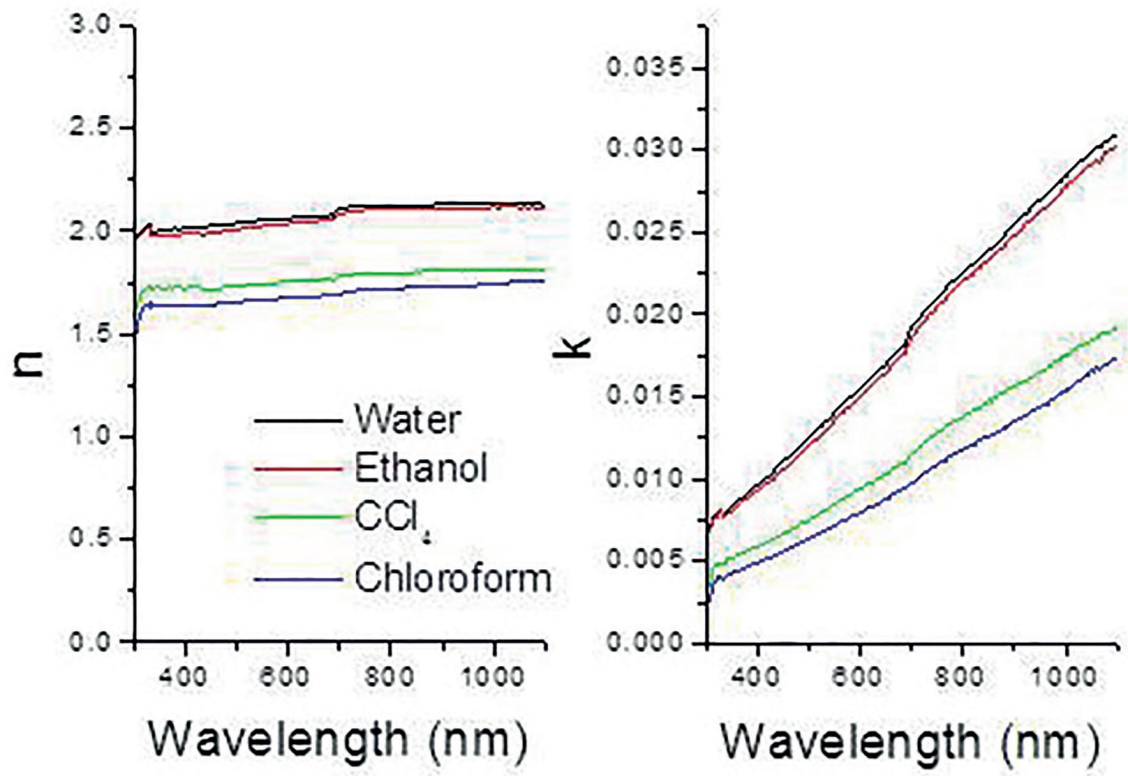

Figure 6: Refractive index (n) and extinction coefficient (k) of CuI thin films produced in different media.

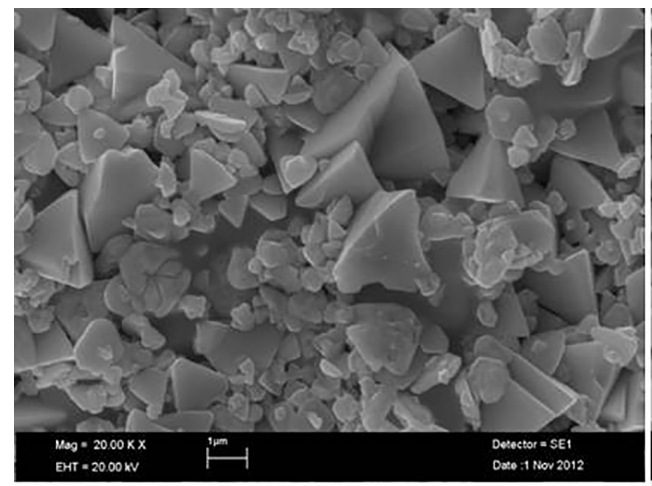

(a)

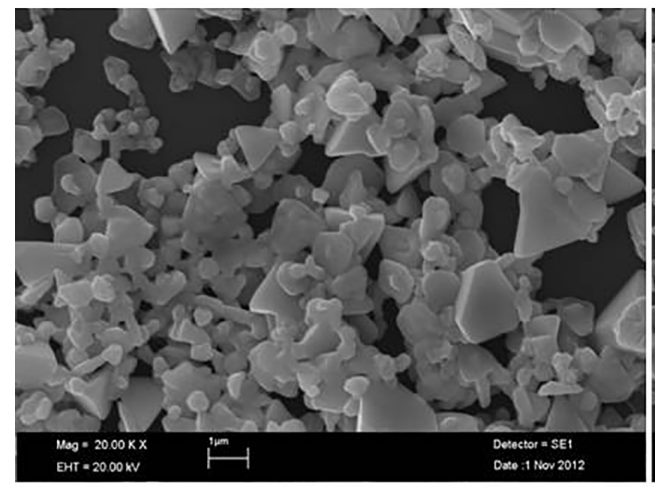

(c)

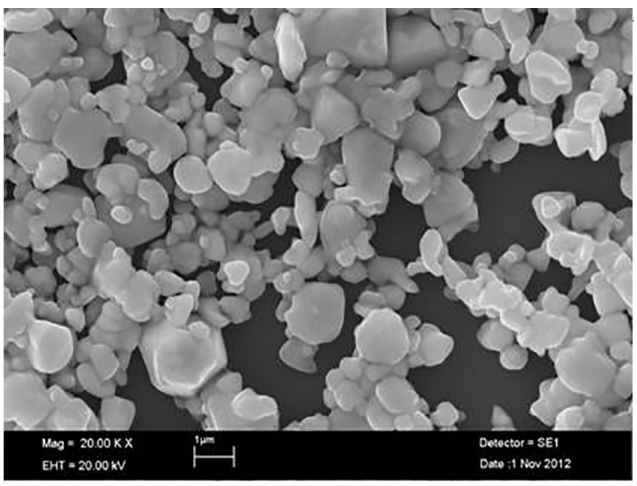

(b)

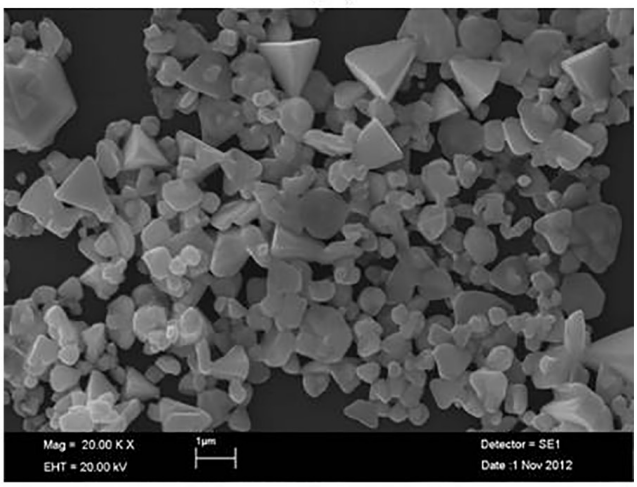

(d)

Figure 7: SEM images of $\mathrm{CuI}$ thin films.

films were in line with their optical properties. The lowest transmittance, the highest refractive index, and regular grain structure of $\mathrm{CuI}$ thin films were observed in the films produced in water and ethanol baths ${ }^{9}$. Kosta et al. have also identified pebble structure for $\mathrm{CuI}^{18}$. The quality of the films that we have produced on amorphous glass through a simple, 
easy and cheap method is similar to the quality of the ones that Kosta et al. have produced through electrochemical method on a crystalline structure; a similar type of surface can be seen in Figure 7a. Grundman et al, who showed that they have produced the most regular structure through SEM images, have captured particle structures similar to triangular prism, as can be seen in our SEM images ${ }^{19}$. Bu all these researchers have attempted to growth crystalline film on crystal substrates using devices.

The EDX technique was used to estimate the composition of $\mathrm{CuI}$ thin films. Figure 8 shows the average elemental molar ratio of $\mathrm{Cu} / \mathrm{I}$ as a factor of chemical bath solvents. It was seen that $\mathrm{Cu} / \mathrm{I}$ ratio has been changed with chemical bath's solution. EDX results indicate that the average elemental molar ratio of $\mathrm{Cu} / \mathrm{I}$ was nearly equal to its stoichiometric ratio in the ethanol solution (elemental molar ratio of $\mathrm{Cu} / \mathrm{I}=$ 0.458 and elemental ratio of $\mathrm{Cu} / \mathrm{I} 29.06 \% / 70.94 \%=0.409$ ). The theoretical elemental molar ratio of $\mathrm{Cu} / \mathrm{I}$ is 0.459 and elemental ratio of $\mathrm{Cu}$ is $29.16 \%$ and $\mathrm{I}$ is $70.84 \%$. The EDX results are in line with XRD and SEM measurements. Since the solubility of iodine and $\mathrm{CuI}$ is higher in chloroform and carbon tetra chloride, $\mathrm{Cu}^{2+}$ ions were stuck to the surface of the substrate with the film because of the incarceration mechanism.
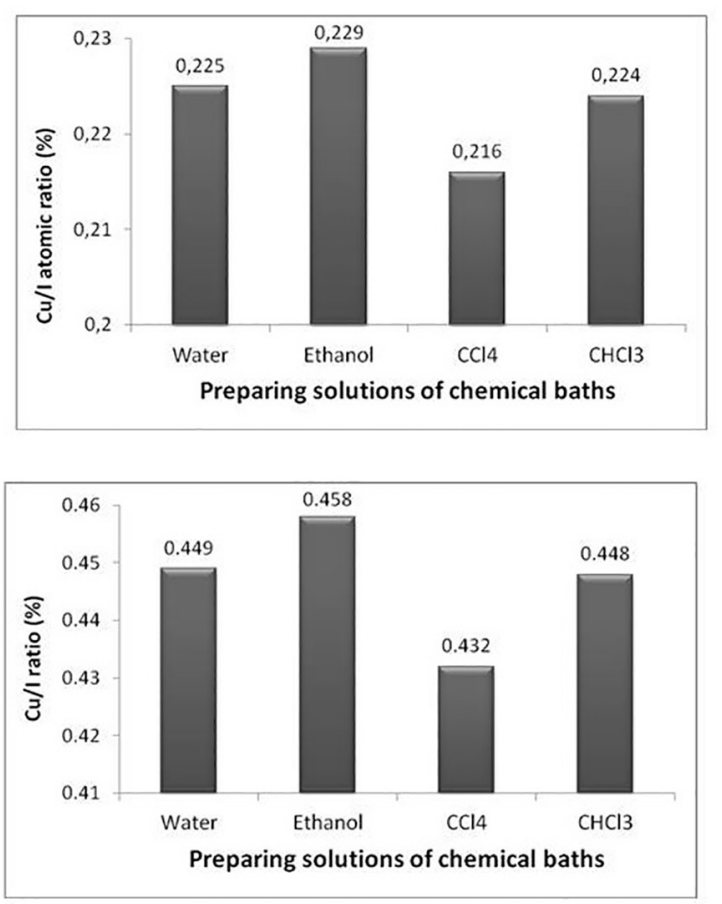

Figure 8: EDX analysis of CuI thin films produced in different media.

\section{Conclusion}

$\mathrm{CuI}$ thin film attracted the attention of the researchers because of its ionic conductivity, thus in this study we discussed what kind of $\mathrm{CuI}$ films we can produce using extraction method, which is very often used by organic chemists. The aim of this study is to decide which media or solvent should be used in chemical bath for producing better $\mathrm{CuI}$ thin films. As a result, it has been found that $\mathrm{CuI}$ thin films produced in the water bath had the best crystalline form; their average grain size and film thickness were higher than the others according to XRD calculations and SEM images. Films produced in chloroform and carbon tetra chloride baths had the lowest film thickness; they were coated only on the half of the glass material. Although commercial glass is very cheap, ITO or FTO substrates are quite expensive. So, this method is not suitable for producing thin films on ITO or FTO. Finally, the film thickness and grain size can change with bath media and this is a very useful and cheap method for producing $\mathrm{CuI}$ in ethanol media. In addition, the ratio of $\mathrm{Cu} / \mathrm{I}$ in ethanol media is almost equal to its theoretical ratio. At the same time, due to their spectroscopic properties, these films can also be used in scintillation applications. Thalliumactivated $\mathrm{NaI}$ crystals are used to measure low-energy $\mathrm{X}$-and gamma rays. $\mathrm{CuI}$ thin films can be used instead of it, which will be more handy and ergonomic.

\section{Acknowledgement}

This study is supported by Erciyes Üniversitesi Teknopark (ETTO).

\section{References}

1. Zheng-Johansson JXM, McGreevy RL. A molecular dynamics study of ionic conduction in CuI. II. Local ionic motion and conduction mechanisms. Solid State Ionics. 1996;83(1-2):35-48.

2. Zheng-Johansson JXM, Ebbsjö I, McGreevy RL. A molecular dynamics study of ionic conduction in CuI. I. Derivation of the interionic potential from dynamic properties. Solid State Ionics. 1995;82(3-4):115-122.

3. Miyake S, Hoshino S, Takenaka T. On the Phase Transition in Cuprous Iodide. Journal of the Physical Society of Japan. 1952;7:19-24.

4. Bührer W, Hälg W. Crystal structure of high-temperature cuprous iodide and cuprous bromide. Electrochimica Acta. 1977;22(7):701-704.

5. Tennakone K, Kumara GRRA, Kumarasinghe AR, Wijayantha KGU, Sirimanne PM. A dye-sensitized nano-porous solid-state photovoltaic cell. Semiconductor Science and Technology. 1995;10(12):1689-1693.

6. Tennakone K, Kumarasinghe AR, Sirimanne PM, Kumara GRRA. Chlorophyll-sensitized microporous copper iodide photocathode. Journal of Photochemistry and Photobiology A: Chemistry. 1995;91(1):59-61.

7. Tennakone K, Kumara GRRA, Kumarasinghe AR, Sirimanne PM. The enhancement of the photocurrent of a methyl violet sensitized cuprous iodide photocathode by $\beta$-cyclodextrin. Journal of Photochemistry and Photobiology A: Chemistry. 1996;96(1-3):167-169. 
8. Tennakone K, Kumara GRRA, Kottegoda IRM, Perera VPS, Aponsu GMLP, Wijayantha KGU. Deposition of Thin Conducting Films of CuI on Glass. Solar Energy Materials and Solar Cells. 1998;55(3):283-289.

9. Huang B, Zheng Z, Yang F, Zhang Y, Pu D, Zhao H, et al. A rapid sonochemical approach to semiconductor thin films: The case of metal iodides. Solid State Ionics. 2008;179(35-36):2006-2010.

10. Sirimanne PM, Soga T, Kunst M. Observation of microwave conductivity in copper iodide films and relay effect in the dye molecules attached to CuI photocathode. Journal of Solid State Chemistry. 2005;178(10):3010-3013.

11. Cullity BD. Elements of X-ray Diffraction. 2nd Ed. Reading: Addison-Wesley; 1978.

12. Mott NF, Davis EA. Electronic Processes in Non-Crystalline Materials. Oxford: Clarendon Press; 1979. p.273-274.

13. Mamazza Jr RF, Morel DL, Ferekides CS. Transparent conducting oxide thin films of $\mathrm{Cd}_{2} \mathrm{SnO}_{4}$ prepared by RF magnetron cosputtering of the constituent binary oxides. Thin Solid Films. 2005;484(1-2):26-33.
14. Ferro R, Rodriguez JA, Vigil O, Morales-Acevedo A. Chemical composition and electrical conduction mechanism for CdO:F thin films deposited by spray pyrolysis. Materials Science and Engineering: B. 2001;87(1):83-86.

15. Callister WD. Materials Science and Engineering - An Introduction. New York: John Wiley and Sons; 1997.

16. Pejova B, Grozdanov I, Tanuševski A. Optical and thermal band gap energy of chemically deposited bismuth(III) selenide thin films. Materials Chemistry and Physics. 2004;83(2-3):245-249.

17. Yan YH, Liu YC, Fang L, Lu ZC, Li ZB, Zhou SX. Growth of $\mathrm{CuI}$ buffer layer prepared by spraying method. Transactions of Nonferrous Metals Society of China. 2011;21(2):359-363.

18. Kosta I, Azaceta E, Yate L, Cabañero G, Grande H, Tena-Zaera R. Cathodic electrochemical deposition of $\mathrm{CuI}$ from room temperature ionic liquid-based electrolytes. Electrochemistry Communications. 2015;59:20-23.

19. Grundmann M, Schein FL, Lorenz M, Böntgen T, Lenzner J, von Wenckstern H. Cuprous iodide - a p-type transparent semiconductor: history and novel applications. Physica Status Solidi A. 2013;210(9):1671-1703. 